\title{
As concepções de adolescência construídas por profissionais da Estratégia de Saúde da Família (ESF) ${ }^{*}$
}

\author{
Débora Cristina Fonseca ${ }^{1}$ \\ Sérgio Ozella ${ }^{2}$
}

FONSECA, D.C.; OZELLA, S. The conceptualizations of adolescence constructed by professionals within the Family Health Strategy (FHS). Interface - Comunic., Saude, Educ., v.14, n.33, p.411-24, abr./jun. 2010.

This paper examines the meanings constructed around adolescence, with their implications for the practices of physicians and nurses working within the Family Health Strategy (FHS) in a municipality in the interior of the State of São Paulo. The analysis was based on interviews and showed that immobility regarding collective actions was reinforced by predominance of a natural, universal and pathological view that positioned adolescence at a place not within the work routine of family health teams. For this reason, there is a need to rethink the conceptualizations, starting from the position that these professionals occupy in the labor market.

Keywords: Adolescence. Family Health. Sociohistorical psychology. Human resources formation.
Este trabalho examina os sentidos construídos sobre adolescência, com suas implicações na prática de médicos e enfermeiros, integrantes da Estratégia de Saúde da Família (ESF) de um município do interior paulista. A análise, com base em entrevistas, constata que o imobilismo para ações conjuntas é reforçado pelo predomínio da visão natural, universal e patológica, que coloca a adolescência no não lugar do cotidiano das equipes de saúde da família. Por isso, a necessidade de se repensar concepções a partir do lugar que tais profissionais ocupam no mundo do trabalho.

Palavras-chave: Adolescência. Saúde da Família. Psicologia sócio-histórica. Formação profissional de recursos humanos.

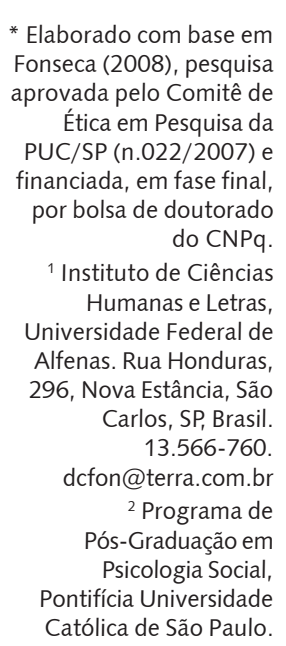




\section{Introdução}

No Brasil existem leis que garantem ao adolescente a prerrogativa de ser tratado como sujeito de direitos, cabendo políticas públicas que possibilitem o seu desenvolvimento pleno e, na área da saúde, o direito à igualdade e universalidade no atendimento de suas necessidades.

Com as garantias legais e, mais recentemente, com a aprovação da Política Nacional de Atenção à Saúde de Adolescentes e de Jovens (Brasil, 2007), a responsabilidade pelas ações integrais de saúde voltadas a essa população fica colocada na atenção básica, mais especificamente, na Estratégia de Saúde da Família (ESF). Neste sentido, consideramos importante aprofundar o campo de conhecimento sobre os sujeitos que atuam cotidianamente na Estratégia de Saúde da Família, e sobre como a adolescência tem sido compreendida por eles e evidenciada no contexto da saúde, pois a efetividade das ações, sobretudo nas áreas de saúde e educação, não tem sido percebida nos dados apontados por vários órgãos e institutos (IBGE, IPEA, Relatório de Desenvolvimento Juvenil 2007, Mapa da Violência 2006 e outros).

Tendo como pressuposto que qualquer concepção ou sentido não estão apartados de um contexto histórico, mas se produzem na relação entre os homens, mediados pelas condições objetivas de vida desses sujeitos, pela sua história e simbolização, na perspectiva apontada por Vigotski (1983), Bock e Aguiar (2003), Aguiar e Ozella (2006), procuramos captar os sentidos construídos pelos profissionais, sem fragmentar o pensamento e o processo de desenvolvimento da consciência. Para isso, buscamos contextualizar social e historicamente esses processos, primeiramente de forma macro e, depois, atrelando ao universo de vivência e existência dos sujeitos.

Do ponto de vista do conhecimento produzido sobre adolescentes/jovens, é possível evidenciar a hegemonia na concepção. No trabalho de revisão teórica sobre as concepções de adolescente/adolescência ${ }^{3}$ no discurso da saúde pública, Peres e Rosenburg (1998) apontam como o modelo biomédico é predominante, trazendo implicações importantes para a prática, tais como: a universalização e naturalização da adolescência, quando se trata de sujeitos concretos, seguindo um padrão de adolescente, caracterizado pela condição de vulnerabilidade, definido pela epidemiologia. Isso significa dizer que, neste modelo/paradigma, se desconsideram a vivência e significação dos processos de construção dos sujeitos em geral, e, neste caso específico do adolescente, tratam-se, de forma homogênea, as questões que envolvem um determinado grupo de pessoas.

Nessa ótica, o paradigma biomédico acentua o sentido de adolescência na perspectiva desenvolvimentista, considerando uma etapa de transição entre a infância e a idade adulta, entendendo como natural e universal esta mudança, independentemente das condições concretas de existência do sujeito. Essa perspectiva e a noção de crise, marcada por tormentos e conturbações, definida e delimitada por alguns autores como "Síndrome Normal da Adolescência", se evidenciam nos contructos produzidos pela área da saúde (Marcelli, Braconnier, 2007; Heidemann, 2006; Taquet et al., 2005; Ávila, 1999; Cano et al., 1998; Oliveira, Egry, 1998; Silva, Pinotti, 1987). Dessa forma, essa compreensão respalda um olhar sobre a adolescência na perspectiva do que é ou não normal em um determinado período cronológico de vida e do desenvolvimento biopsíquico. Assim, a formação e a prática dos profissionais ficam norteadas pelos parâmetros de tempo e comportamentos esperados, diagnosticando-se processos de mudança como de "adoecimento" na adolescência. Esses posicionamentos foram por nós entendidos como naturalizantes, universais e patológicos por conceberem a

\author{
${ }^{3}$ Discussão importante \\ sobre o uso das palavras \\ adolescente e \\ adolescência como \\ sinônimas encontra-se no \\ trabalho de Peres e \\ Rosenburg (1998), de \\ grande importância para \\ a compreensão das \\ práticas em saúde, \\ porém, neste momento \\ não se fará distinção no \\ uso dos termos.
}


adolescência como uma fase do desenvolvimento, quando inevitavelmente se vivenciará a crise ou conflitos inerentes a essa idade.

Posicionamentos diferenciados são encontrados, mas ainda de forma incipiente, para romper com o modelo hegemônico em Ferrari, Thonson, Melchior, 2006; Ventura, 2006; Leão, 2005; Assis et al., 2003; Bastos, 2003; Catharino, 2002; Mendonça, 2002; Ayres, França, 2000; Calazans, 2000; Formigli, Costa, Porto, 2000, e outros.

O referencial teórico que respalda nossa reflexão sobre adolescência e sentidos construídos pelos profissionais de saúde é o da psicologia sócio-histórica, cuja base epistemológica se apoia no materialismo histórico dialético. A concepção de homem e de mundo que partilhamos passa pela negação de uma natureza humana e a entende como construídos, histórica e socialmente, nas condições concretas de existência. Assumimos como categoria de análise principal, neste trabalho, a compreensão de sentido, no movimento dialético entre pensamento e linguagem, na perspectiva discutida por autores como Vigotski (2001, 1984, 1983), Lúria (2001), Leontiev (1978), Aguiar e Ozella (2008, 2006).

Assim, a adolescência é compreendida como um momento de um processo e, como tal, em construção, que pode ser diferente do que está sendo para o próprio adolescente e para uma sociedade. É entendido como não natural e universal, mas produto de sua história de vida, enquanto sujeito pertencente a um grupo social, a uma cultura, da qual recebe influência e sobre a qual age dialeticamente; não desenvolvimentista, pois cada sujeito o vivenciará de uma maneira, dependendo de suas interações sociais, do desenvolvimento de seus interesses, de suas necessidades e da significação que as mudanças biológicas têm ou tiveram; e não patológico, no sentido de que não vivenciar as mesmas coisas que outro adolescente - por exemplo, a chamada crise da adolescência - pode ser saudável, possibilitando que cada um seja sujeito de sua própria história, capaz de fazer suas escolhas dentro de suas possibilidades objetivas e subjetivas, desenvolvendo uma autoconsciência e autonomia diante do contexto. Essa compreensão não nega as mudanças biológicas, mas as entende também como significadas histórica e socialmente (Aguiar e Ozella, 2008; Ozella, 2003; Vigotski, 1984).

Nesse contexto, buscamos refletir sobre o que significa, no cotidiano das equipes de Saúde da Família, esta (nova) atribuição, não só no aspecto da demanda, mas sobretudo na forma como esses profissionais olham a população denominada adolescente/jovem e suas necessidades de saúde.

\section{Metodologia}

A pesquisa de campo foi realizada em um município paulista, com população de 213 mil habitantes, credenciado junto ao Ministério da Saúde em Gestão Plena, que conta com uma rede de atendimento à saúde pública, na atenção básica, composta por 12 Unidades Básicas de Saúde (UBS) urbanas, uma rural, e 11 Unidades de Saúde da Família com 12 equipes. Ocupa o $17^{\circ}$. lugar no ranking dos municípios paulistas, com IDHM de 0,84 (2000), PIB (2006) 3.137,11 (Fundação Seade, 2009), sendo considerado polo de desenvolvimento científico e tecnológico (tem duas universidades públicas e três particulares).

Para a coleta de informações, foram utilizadas entrevistas semiestruturadas, realizadas individualmente com todos os profissionais médicos e enfermeiros que compõem as 12 equipes (22 profissionais, considerando-se que duas equipes encontravam-se incompletas) existentes no município pesquisado, naquele momento. Com o conhecimento dos sujeitos, passamos a definir aqueles cuja análise qualitativa seria realizada, visando aprofundar a compreensão sobre eles, considerando como critérios:

1 O conteúdo da entrevista o mais completo possível em termos de informações, ou seja, o profissional colocou-se de forma detalhada nos pontos principais, considerados a partir dos objetivos de pesquisa; 2 As entrevistas que representavam os dois principais grupos de profissionais evidenciados: profissionais que tiveram uma formação tradicional e uma experiência profissional maior, e que recentemente passaram a integrar a ESF; o segundo grupo: profissionais com formação recente, já com um direcionamento, a partir da graduação, para a ESF, e experiência profissional focada na ESF.

Definimo-nos pela análise aprofundada de quatro entrevistas, sendo os sujeitos dois médicos (M5 e M6) e duas enfermeiras (Enf. C e Enf. J). Considerando que, na pesquisa qualitativa, o número de 
sujeitos analisados não é a referência principal, mas os elementos que possibilitam um aprofundamento na compreensão, entendemos que esses quatro profissionais seriam suficientes para os objetivos da pesquisa. Eles trabalhavam em USF periféricas, atendendo a população pobre. Dos quatro serviços, dois já tiveram experiências de trabalhos com grupos de adolescentes, mas no momento da pesquisa faziam apenas atendimentos pontuais.

Foi realizada a leitura atenta de cada entrevista com o objetivo de levantar os pré-indicadores, que consistem em expressões significativas do discurso, seja pelo conteúdo, repetição, entonação, seja por outras formas possíveis de se evidenciar uma significância para o sujeito. A seguir, eles foram agrupados pelo que apontavam, de forma a organizá-los como indicativos de um sentido. Como terceiro momento e início de análise propriamente dito, agrupamos os indicadores por núcleos de sentido, organizando-os de maneira que nos possibilitassem compreender os sentidos construídos pelos sujeitos, de forma a não fragmentar a construção do pensamento. Esta metodologia de análise está mais bem descrita por Aguiar e Ozella (2006) e Fonseca (2008).

Neste artigo, nos deteremos na análise dos núcleos que versam sobre a compreensão de adolescência e o lugar dessa população na área da saúde, no contexto da ESF. A análise dos demais núcleos, bem como suas relações e articulações podem ser encontradas em Fonseca (2008).

\section{Análise e discussão}

Os sentidos construídos pelos sujeitos são singulares, não obstante é possível apontar para aspectos semelhantes dos discursos e construção de sentidos. Passamos à elaboração de considerações sobre os quatro profissionais de saúde, na perspectiva de captar elementos dos discursos e da construção de sentidos sobre adolescência e ESF que possam ajudar a compreender como suas concepções interferem no cotidiano dos serviços das USF.

\section{Concepções de adolescência}

Na fala dos profissionais, a adolescência fica entendida como uma fase de desnorteio, dificuldades, desencontros, confusão e vulnerabilidade, correspondendo ao modelo de adolescência social e culturalmente predominante, que nomeamos de visão universalizada, natural e patológica, já que em nenhum momento esses profissionais indicam a compreensão de que adolescência possa ser diferente para cada sujeito, em cada cultura. Universalizam como uma fase "conflituosa", como ilustram os trechos abaixo.

\footnotetext{
“A minha compreensão de adolescência, eu sempre vivi isso aqui, sempre que tenho a oportunidade, é uma fase terrível de absoluto desnorteio tanto da família quanto do adolescente". (M6)

“Olha, adolescência é uma coisa muito... é meio nó, é meio que atração hoje [...] eu vejo os adolescentes como um período de transformação do corpo, do biológico, que muda, a questão hormonal, a questão do corpo, de aparecer a mama, de aparecer os pêlos pubianos, mas é período de transformação na questão psicológica da pessoa, do momento que ela quer adquirir responsabilidade, ao mesmo tempo não quer assumir, quer curtir a vida, quer ser criança ainda, é um período que é difícil porque faz muito tempo que eu não vejo". (Enf. C)
}

Atribuem ao adolescente algumas características, indicando um entendimento de que elas são naturais, responsáveis pelo conflito vivenciado, como: insegurança, autoincompreensão, desequilíbrio e vulnerabilidade.

“[...] você não é mais criança, mas ao mesmo tempo você [...], não é adulto ainda para você mandar no seu nariz! Então é uma fase de transição em que você perde algumas coisas e não consegue ganhar outras coisas para repor". (M5) 
"O que eu consideraria no adolescente é que nele, por uma questão até da vitalidade orgânica da idade, ele, do ponto de vista orgânico, ele é menos vulnerável às doenças tradicionais, ele já passou a geração da infância, a fase mais crítica ele já venceu. Se ele chegou à adolescência ele provou que a seleção natural foi boa, ele deve ter tido cuidados com relação a doenças de infância e tal. Mas eu acho que nele, é a saúde mental, o emocional dele que muitas vezes não está bom". (M6)

Fica evidente a ideia de fase, caracterizada como de conflito, transição e perda de privilégios da infância. Esses discursos nos indicam que os profissionais parecem ter construído o sentido de adolescência tendo como referência ciclos de vida, concepção marcada por uma ideia de desenvolvimento natural, num crescente de aquisição de recursos físicos, cognitivos e emocionais, que o habilitam a entrar em outras fases da vida. Essa forma de caracterizar a adolescência, entendida como o momento de finalização da formação da personalidade, atribuindo algumas características como inerentes a ela, se aproxima bastante daquela definida por Aberastury e Knobel (1989), com a indicação de uma sintomatologia, que considera, como normal nessa idade, a existência de um certo grau de patologia.

Penso que a estabilização da personalidade não se consegue sem passar por um certo grau de conduta patológica que, conforme o meu critério, devemos considerar inerente à evolução normal desta etapa da vida. (Aberastury, Knobel,1989, p.27)

A essa compreensão Vigotski (1984) teceu críticas, considerando-a biologizante. Para esse autor, o que marca a adolescência não é um processo natural de desenvolvimento, mas, sim, as mudanças radicais em seus interesses, num movimento dialético de crise e síntese, desencadeado pela vivência concreta do sujeito e, também, pelas mudanças biológicas orgânicas. É quando emergem novas necessidades, desenvolve-se a autoconsciência e, consequentemente, uma autonomia, decorrente da revolução nos processos psíquicos.

Parece-nos que, em sua construção de sentido de adolescência, os profissionais pesquisados trazem alguns valores socialmente partilhados, que, de forma geral, a universalizam e naturalizam. Tratam-na como fase, como algo natural do ciclo de vida e que, portanto, todos vivenciarão, sem diferença em seus aspectos essenciais, como se observa no contexto das falas.

"A gente entra em conflito: 'Ai, gente, ao mesmo tempo eu quero fazer isso, eu não quero fazer aquilo. Eu gosto da minha mãe, mas eu sinto raiva dela' É... 'Eu gosto da minha irmã, mas ao mesmo tempo eu tenho ciúmes' [...] eu tinha que aceitar que eu tinha a mama grande em relação aos outros, ser uma menina alta em relação às outras, complexo de inferioridade, de você querer se comparar com os outros". (Enf. C)

Parece-nos claro que o sentido de adolescência construído é permeado pelas contradições decorrentes da internalização dos valores pressupostos em sua vida pessoal, do aprendido e vivenciado na formação profissional e da simbolização dela própria. Desta forma, naturalizam e universalizam a adolescência, considerando que existem conflitos e emoções próprias da idade; ao mesmo tempo, contextualizam e atribuem à família certa responsabilidade pelas dificuldades que o adolescente vivencia. Como nos lembra Friedman (1995, p.137): "Os sentidos pessoais referem-se a enlaces ou relações atribuídas às palavras no confronto entre as significações sociais vigentes e a vivência pessoal".

Essa visão hegemônica é questionada por autores que compreendem a constituição e desenvolvimento humanos como produto do social, sendo a adolescência um momento significado por cada cultura, podendo até mesmo não existir com os significados construídos nas sociedades capitalistas. Segundo Vigotski (1984), a marca dessa idade consiste no salto qualitativo nas funções psicológicas e no caráter pessoal que adquirem os atos psíquicos, e não numa predeterminação inerente à natureza humana. O sentido de adolescência é muito mais amplo que o significado expresso na palavra conflito, refletindo sua história de vida, e articulando os eventos psicológicos produzidos por ela, frente à realidade (Aguiar, Ozella, 2006). 
Podemos considerar que esses profissionais, em seus sentidos construídos, demonstram o entendimento de uma natureza humana dividida por ciclos de vida (fases), pela qual todos passarão, independentemente da cultura e do grupo social a que pertencem. Entretanto, apreendemos um processo, e não uma fixação, nestas concepções ao indicarem ações coletivas, mas ainda muito focadas em problemáticas, socialmente consideradas da chamada "fase adolescente".

Os sentidos contraditórios de adolescência captados nos discursos nos mostram que estes profissionais estão na busca de liberdade de pensamento, no sentido apontado por Vigotski (1983), quando lembra que o livre-arbítrio não consiste em estar livre dos motivos, mas sim em tomar consciência da situação, da necessidade de escolha que os motivos Ihe impõem. Portanto: "La liberdad humana consiste precisamente en que piensa" (Vigotski, 1983, p.288).

\section{Adolescência, saúde e ESF}

Os sentidos construídos pelos profissionais participantes da pesquisa sobre adolescência e sobre o trabalho com essa população dentro da ESF trazem sempre o elemento de mudança, um entendimento de que a área da saúde deve se responsabilizar pelo cuidado, na ótica da integralidade. No movimento de construção de suas consciências e pensamentos, percebem o "não lugar" do adolescente nos serviços de saúde e na formação profissional. Os sentidos são necessidades que ainda não se realizaram, mas que mobilizam o sujeito para a ação (Aguiar, Ozella, 2006, p.227), como podemos observar nas considerações a seguir.

Quanto à construção de sentido sobre a ESF, por esses profissionais, podemos apontar que ele está em construção, levando os sujeitos à redescoberta de ideais e de motivações para atitudes criativas e de mudança. Ou seja, a ESF está carregada de sentidos, construídos e atrelados às histórias pessoais dos sujeitos, de formação profissional e experiências profissionais, além de possibilidades de resgate de princípios esquecidos, adormecidos, que foram, em sua maioria, construídos nas relações familiares. Um exemplo está na fala de M6, que afirma que na ESF pode resgatar a medicina que aprendeu com o próprio pai e avô.

"O que significa para mim, hoje, eu posso dizer para você que o que significa é a realização profissional. Eu nunca fui tão feliz em toda a minha vida, nos meus quase cinquenta anos como eu sou feliz hoje, o quanto eu sou realizado. Olha que aqui, como em todas as Unidades, o trabalho é intenso, ele é denso. Mas, ele é potente no sentido de gratificar cada profissional. [...]. Então [...] se eu partir hoje, eu parto feliz porque eu finalmente consegui fazer a Medicina que o meu pai e o meu avô lá em [...] preconizaram. Eram médicos das antigas que eles falavam: 'Você é médico de antigamente', como eu ouço hoje alguns colegas de maneira muito depreciativa se referindo a Saúde da Família, que nós somos saudosistas, que nós queremos trazer a Medicina do passado. Mas, para mim, é a realização". (M6)

Encontramos aqui uma das teses centrais do materialismo histórico-dialético, que consiste na unidade dos contraditórios, na indissociabilidade entre pensamento e afeto, entre simbólico e emocional, considerando, segundo Aguiar e Ozella (2006), que todas as expressões humanas são cognitivas e afetivas. Este sentido de ESF é permeado de emoções e de afetividade.

“Para mim, eu amo a saúde da família. Eu acredito que não é a solução pro SUS totalmente, eu acho que precisa de várias mudanças, mas é... [...] uma estratégia para tentar reorganizar um Sistema Público de Saúde que no papel é lindo, a integralidade da assistência, para mim, a saúde da família é uma possibilidade de exercer a integralidade da assistência, olhar o indivíduo de uma forma mais ampla, mais singular, olhar a família de uma forma mais singular, procurar... é o facilitador no sentido de gerar equidade". (Enf. C) 
“Então, vejo que a estratégia Saúde da Família ela aproveitou tudo o que um primeiro projeto tinha de bom e ele ampliou muito isso. Essa questão do cuidado porque hoje nós vemos a saúde não mais aquela questão: "Eu vou tratar". Não, não, eu não sou um curandeiro, eu não sou só um cientista, eu não sou só um... eu sou um cuidador! [...] Eu demorei para entender um pouco isso, "mas eu trato tão bem meus pacientes, eu sou gentil, eu sou atencioso, eu procuro me informar, eu acho que eu tenho competência, saber", mas não é só isso. O cuidado é muito mais do que isso". (M6)

Na visão sócio-histórica, entende-se que o sujeito é afetado pelo mundo e vivencia essa experiência com muitas possibilidades de sentidos, construindo seu mundo psicológico ao mesmo tempo em que interfere no mundo, pela atividade e mediação da linguagem. Para Vigotski (2001), os afetos são estados corporais que aumentam ou diminuem a capacidade do corpo para a ação.

Nesse processo de afetação, os sentidos da ESF vão se construindo mediados pelos vários elementos vivenciados pelos sujeitos; a relação entre pensamento e linguagem possibilita a construção de uma consciência crítica, como podemos observar no trecho abaixo:

\begin{abstract}
"Mas eu acho assim, sem medo de errar: mais de 90\% não está preparado para lidar com coisa nenhuma, ele só sabe lidar com doença. Quando ele vai lá e vê uma pessoa com queixas inespecíficas: [...] não sabe lidar com isso. Por quê? Vai lá, pede eletro, hemograma, um monte de exame de sangue, não sei o quê, vem tudo normal. 'Esse não tem nada', fala para o paciente [...] na verdade falta médico! Tem muito técnico em medicina! Técnico em medicina, que foi lá e estudou para ser marceneiro, ferramenteiro, serralheiro, tem um monte. Agora, médico, que está afim de chegar dentro da pessoa, ver o que ela está precisando, jogar junto com ela, viver um pouco com ela e tentar ajudá-la é muito pouco". (M5)
\end{abstract}

Aqui, também, entendemos que a crítica está fundamentada em suas experiências de vida. Deparamo-nos com o desenvolvimento da consciência, de forma crítica, constituída e mediada pela linguagem e pela atividade. Leontiev (1978) lembra que a consciência não é imutável, devendo ser considerada em seu processo de desenvolvimento; depende das condições concretas de existência do sujeito (modo de vida e relações sociais existentes), que consistem em transformações qualitativas no pensamento, o que Vigotski (1983) nomeou de função psicológica superior.

No movimento de construção da consciência crítica, podemos captar no discurso de M5 o seu convencimento da diferença mencionada anteriormente, já que compreende que médico é aquele que está preocupado realmente com as necessidades das pessoas. Os demais são considerados por ele como técnicos em medicina. O mesmo se evidencia quando os profissionais passam a analisar a situação do adolescente no contexto da ESF. Os trechos abaixo explicitam esta percepção:

"Acho que não só na Saúde da Família, mas no sistema de saúde, eu acho que nós ainda não temos - salvo honrosas exceções -, um trabalho que realmente vá ao encontro para resgatar essa população de adolescentes que mais precisam, que estão nas periferias e também os que estão nas mansões, a gente acha que porque eles estão lá eles estão bem servidos, cercados de cuidados, mas na verdade não estão, na maioria dos casos não é muito assim, mas eu acho que nós ainda estamos devendo muito". (M6)

"Não existe trabalho no Saúde da Família para o adolescente [...] Ele não é encarado como uma prioridade porque nós temos, assim, problemas de maior grandeza, por exemplo, as patologias crônicas, a hipertensão diabética, [...] causam comprometimentos, sequelas e morte. [...] Então, o Saúde da Família, ele acaba atacando onde dá mais problema. Então, onde dá mais problema? É quem tem doença crônica, a mulher, principalmente o enfoque no pré-natal e, justamente as crianças. A gente trabalha muito criança até dois anos! Depois disso, não existe esse trabalho". (M5) 
Apesar do entendimento de saúde e doença de forma mais ampla, ao falar de saúde e doença no adolescente, os profissionais pesquisados têm seus discursos permeados por toda uma construção histórica da compreensão de adolescência, evidenciada no primeiro núcleo de análise, ou seja, um sentido universal que os leva a entender a doença no adolescente como emocional, fruto dos conflitos, do desequilíbrio e de circunstâncias naturais na adolescência. Desta forma, não precisa ser priorizada, se comparada com outros grupos populacionais. A construção de sentido ainda tem alguns elementos constitutivos permeados pela noção biologicista decorrentes da formação, negando, assim, toda a história dos sujeitos e as condições concretas de vida, influenciando determinantemente no planejamento de ações cotidianas nos serviços de saúde. Os conflitos e as questões emocionais, vistos como inerentes à fase adolescente, evidenciam e reforçam a naturalização e patologização deste momento de vida, interferindo concretamente nas ações em saúde, como podemos constatar na análise das falas dos profissionais.

“[...] ele pode estar fisicamente hígido, mas emocionalmente, psicologicamente falando, completamente vulnerável e doente, aí diferencia". (M6)

"O adolescente por ser... se achar, não ser, mas se achar super-poderoso, as questões deles quando emperram para eles, doenças, são questões emocionais". (M5)

“No adolescente, ele acha que ele não adoece, né? (risos) Ele se expõe muito fácil a riscos, né? Tem muita vitalidade, ele se acha. A própria formação, a idade, então às vezes acaba adoecendo nas coisas mais graves por essa situação. [...] Para mim o adolescente é muito saudável". (Enf. J)

Consideramos importante a abordagem dos aspectos emocionais como alvo de atenção na saúde do adolescente. Entretanto, a desvinculação com os demais aspectos que produzem saúde e doença acaba colocando neste grupo um elemento patológico como diferenciador dos demais momentos da vida. Tratar como um elemento separado transforma a adolescência num "fenômeno patológico" diante de uma sociedade que adoece cotidianamente, dadas as condições concretas de existência da população, seja pelas questões socioeconômicas, seja pela violência em todas as suas formas. Considerar esse aspecto como o diferencial de saúde e doença pode implicar uma prática em saúde distorcida e, em alguns casos, perigosa à medicalização.

Se analisarmos mais especificamente, podemos entender que a visão patológica predomina também neste contexto, já que o conflito e a insegurança são entendidos como inerentes à adolescência. Assim, constatamos que, para esses quatro profissionais, a adolescência constitui um momento único, decorrente do processo de desenvolvimento, uma fase pela qual todos irão passar e na qual irão vivenciar conflitos, compreendidos como algo que pode levar ao adoecimento emocional.

Blasco (1997) nos lembra que esses conceitos que naturalizam a adolescência, compreendendo-a como universal e patológica, têm influenciado o cotidiano dos trabalhos desenvolvidos com e para adolescentes, e questiona sobre as consequências de tratá-la como crise ou fase de conflito. Nesta perspectiva, entendemos que tal compreensão paralisa e dificulta a intervenção junto à população adolescente, especialmente quando se trata dos profissionais da ESF, que deveriam atentar para vários problemas enfrentados por ela e que não são percebidos porque, geralmente, são vistos ou confundidos como problemas inerentes ou normais da idade. Também se reflete na não identificação do adolescente com o serviço de saúde, o que justifica a baixa demanda. Ainda, pode dificultar a observação de outros aspectos relevantes e importantes de serem cuidados com os adolescentes (questões entendidas como sociais, mas que estão diretamente relacionadas à área da saúde, como a violência).

Em decorrência, os participantes dessa pesquisa acreditam que os profissionais da área tenham dificuldades de trabalhar a saúde do adolescente por falta de embasamento teórico e pela organização dos serviços, e que, consequentemente, eles (adolescentes) acabam ficando sem atenção, sem a organização de uma estratégia que vá ao seu encontro. 
“E... hoje eu não trabalho muito porque é nesse momento que eu estou em conflito, mesmo, como trabalhar com adolescente porque eu não tenho isso muito estruturado. E aí eu falo: "Como eu posso dar para o outro o que eu não tenho?" E aí a equipe está tentando reestruturar, a gente está tentando... a gente vai procurar estudar, consultoria, ver dinâmica, fazer dinâmica com a gente para ver se está claro e depois estudar com adolescente". (Enf. C)

\footnotetext{
"Por outro lado, acho que nós, profissionais da saúde, deixamos muito a desejar, precisamos ainda de uma capacitação, de treinamento, de um aperfeiçoamento para falar o linguajar do adolescente, para nos aproximarmos mais dele através de programas especiais, não de uma coisa muito fechada, enquadrar em caixinhas, não, uma coisa bem com a cara do adolescente". (M6)
}

Apesar de o sentido pessoal de adolescência dos profissionais estar bastante permeado pela concepção naturalizada, universal e patológica, eles também apontam as instituições formadoras como responsáveis pela deficiência na formação e pela exclusão do adolescente nos serviços de saúde.

Podemos, assim, considerar que esses profissionais, guardadas as devidas diferenças de construções pessoais, trazem arraigado à sua concepção de adolescência o pressuposto de uma natureza humana predeterminada, sobretudo em seu aspecto evolutivo desenvolvimentista, considerando-a uma fase da vida conflituosa, tal como tem sido tomada por vários autores, citados no início deste artigo. Entretanto, compreendem que essa é uma condição que pode ser, em alguma medida, alterada, responsabilizando a sociedade, especialmente as instituições de ensino e de saúde, pelo trabalho.

Ao atribuírem à formação pessoal algumas dificuldades, apontando falhas no que se refere à adolescência, acreditam que o que modificaria esse quadro seria um preparo que levasse a problematizar e discutir a adolescência. Neste processo, conseguem olhar para sua própria formação, enquanto categoria profissional, e considerar aspectos importantes que afetam a prática cotidiana dos serviços de saúde.

“Eu me lembro [...] que ao longo do curso, o professor me chamava, chamava o grupo de colegas e dizia assim: 'Olha, eu quero mostrar para vocês lá na enfermaria 5 um fígado'. 'Ah, está bem'. Então dava a impressão de que nós iríamos lá e íamos encontrar um fígado em cima da mesa, tamanha a fragmentação do paciente que se tinha". (M6)

"Acho que a maior dificuldade nossa é essa... é nos organizar para fazer a atividade educativa. [...] Eu acho que a dificuldade é essa: nós não estarmos atrelados com a questão da demanda e ainda a gente não tem tido perna para ampliar esse trabalho de atividade educativa". (Enf. J)

Entretanto, se contradizem ao apresentarem, como dificuldades para o profissional, as características da adolescência. A prática e a vivência na ESF parecem ser um elemento significativo na reformulação de suas concepções, demonstrando uma abertura para reverem e avançarem neste processo, como fica indicado em vários momentos de seus discursos, quando apontam, como empecilhos para o profissional de saúde: o despreparo, a falta de capacitação que dificulta, por exemplo, a aproximação com o adolescente e a criação de vínculo.

A forma pontual com que a adolescência tem sido focada no contexto da saúde e da Saúde da Família foi outro destaque dos sujeitos, que a avaliaram como pouco efetiva, indicando que a predominância do modelo médico-centrado e do tratamento medicamentoso não abre espaço para o adolescente buscar os serviços de saúde e, assim, perceber a Unidade de Saúde como referência, mesmo porque, do ponto de vista biológico, não adoecem facilmente.

Os profissionais pesquisados tecem críticas à ESF, considerando que não existe, de fato, trabalho em que o adolescente seja o foco. Na revisão bibliográfica, localizam-se algumas experiências interessantes com adolescentes, no campo da saúde, porém ainda muito pontuais, limitadas e inexpressivas (Ventura, 2006; Leão, 2005; Taquet et al., 2005; Mendonça, 2002; Formigli, Costa, Porto, 2000). 
Encontramos, assim, profissionais que já internalizaram e construíram um sentido pessoal para a ESF, mas que ainda estão construindo o significado da prática, do cotidiano de trabalho, de forma que viabilizem esta compreensão de saúde em mudança, que priorizem: o humano, o acolhimento, a escuta, o contexto e o sujeito no processo e na comunidade. Nesse sentido, Martins (2005) lembra que usuários e profissionais da equipe de saúde carregam, em sua prática, sua história individual e social, concepções e pré-concepções já cristalizadas, que podem dificultar mudanças, considerando: "importante relembrar que o cotidiano é o espaço de maior expressão da alienaç̧ão" (Martins, 2005, p.150).

Ao pensar no adolescente dentro da ESF, esses profissionais enfatizam não existir trabalho para eles. Em suas percepções, entendem que o adolescente não é prioridade, por existirem problemas que consideram de maior grandeza, como exemplificou a fala de M5. Ao mesmo tempo, consideram que existe falta de espaço e oportunidades para o profissional aprender a trabalhar, acarretando, mais uma vez, a não priorização da adolescência.

Ao relacionarem a ESF, a adolescência e a prática médica, ficam ainda mais evidentes essas contradições, pois construíram uma representação de que o médico de família tem uma visão melhor sobre o adolescente, mas que, no geral, tem dificuldades de lidar com queixas inespecíficas desse sujeito, atribuindo um despreparo do médico e do enfermeiro para lidar com essas questões.

Portanto, o sentido parece mediado por uma compreensão biomédica dessa faixa etária, na perspectiva apontada por Peres e Rosenburg (1998). Fica evidente que, nessa construção, a ideia de uma adolescência naturalizada ajuda os profissionais a justificarem o não trabalho com adolescentes. Ao mesmo tempo, a compreensão de saúde e de ESF os leva a assumirem uma "mea culpa", mas, ainda, não como uma responsabilidade pessoal, mas, sim, por decorrência de sua formação, que não os preparou adequadamente.

\footnotetext{
“Então, assim, existe a questão hoje, na Saúde da Família, de não existir, mas de bater lá: 'olha, tem que ter o trabalho com adolescente, planejamento familiar, tem que atender o adolescente na sua micro área, tem que fazer grupo', mas não existe ainda, eu não sei a experiência de outras cidades...". (Enf. C)
}

Nas contradições presentes nos sentidos de adolescência desenvolvidos pelos profissionais pesquisados, no contexto da ESF, parece existir uma intenção, uma mobilização para uma prática mais comprometida, transformadora e coerente com os preceitos do SUS, mas ainda não efetivada, por decorrência de vários aspectos, entre eles, seus valores e sentimentos pessoais que persistem e uma formação deficitária, influenciando o pensar em propostas voltadas à população adolescente. Como nos lembram Aguiar e Ozella (2006, p.228): "as necessidades se constituem e se revelam a partir de um processo de configuração das relações sociais, processo esse que é único, singular, subjetivo e histórico ao mesmo tempo".

Coerente com essa compreensão, podemos perceber, por exemplo, que a Enf. C aponta o trabalho com adolescentes dentro da ESF teoricamente como um instrumento importante para viabilizar ações para eles. Por ser uma estratégia, dá abertura para planejar o cuidado e a assistência adequada ao adolescente, bem como o planejamento de trabalho em grupo, que, segundo ela, é a base para o trabalho com esse público. Porém, na prática, parece ainda não existir qualquer trabalho efetivo.

Esses profissionais indicam ter uma visão ampla e clara desse não lugar do adolescente no contexto da saúde $e$, de forma crítica, apontam os fatores que contribuem para a manutenção dessa situação. $A$ visão política do espaço da saúde parece-nos uma referência importante na construção de sentido de trabalho na área, permitindo uma análise conjuntural do que não existe. Porém, essa visão parece ainda não ter conseguido ultrapassar a linha da análise e vislumbrar propostas que transformem a prática.

Percebemos que existem coerências e contradições, entre como pensam a ESF e como concebem o trabalho com adolescentes. Captamos, assim, um movimento dialético na relação entre pensamento e linguagem (Vigotski, 2001), contribuindo para um fazer cotidiano em relação à adolescência articulado com sua concepção de sujeito adolescente. Portanto, um sentido dinâmico, fluido e complexo, que tem por base uma concepção de homem e de mundo, que coloca as necessidades de saúde do adolescente como importantes e fundamentais no trabalho cotidiano das equipes de Saúde da Família. 


\section{Considerações finais}

De forma geral, pareceu-nos existir um imobilismo dos profissionais pesquisados, para ações conjuntas voltadas a esse público. Entendemos que grande parte desse não lugar e da paralisia dos serviços de saúde possa ser decorrente do predomínio da visão natural, universal e patológica. Tal relação merece um aprofundamento, não permitido nos limites deste trabalho, mas que consideramos fundamental para o avanço no conhecimento da área de saúde e para o desenvolvimento de práticas mais efetivas e emancipatórias no cuidado com a saúde integral do adolescente.

Entretanto, podemos apontar, com base neste estudo, que, se o olhar sobre a adolescência fosse reconstruído, na perspectiva de que o modo de ser adolescente é resultante da cultura e do grupo social em que cada um está inserido, sendo sua história de vida e de simbolização a responsável por novas formas de se comportar, provavelmente os profissionais se sentiriam mais capazes de intervir no processo. Compreendendo a adolescência como uma construção social, que pode ser experienciada e significada de maneiras diferentes, como o momento em que ocorrem mudanças revolucionárias nos interesses e o desenvolvimento da autoconsciência, os processos educativos passariam a ter papel fundamental nas ações em saúde, podendo de fato ser pensados na perspectiva da integralidade e do cuidado, como proposto por Ayres (2007).

A partir das falas e dos sentidos captados, construímos uma compreensão de que, nos moldes atuais, a ESF, em sua metodologia, está materializando sua proposta de maneira incoerente com sua concepção. Evidenciamos sentidos construídos sobre a ESF na perspectiva da integralidade e do cuidado, mas, quando discursam sobre o cotidiano de trabalho, apontam para uma prática fragmentada, resultante da apropriação do modelo organizativo da ESF.

Pela ótica da metodologia implantada, o adolescente parece ocupar um "não lugar", sob o argumento de que ele não apresenta problemas de saúde, e, na fala de alguns profissionais, os adolescentes não ficam doentes.

O "não lugar" da adolescência acaba aparecendo de maneira mais contundente quando os profissionais são questionados e, de certa forma, levados à reflexão sobre suas práticas. Estabelece-se o conflito entre suas concepções, seus sentidos construídos sobre a ESF e saúde, as condições reais de trabalho e seus sentidos pessoais que norteiam a compreensão de adolescência.

Ao mesmo tempo, parece existir um grande esforço, ainda que cognitivo, para a superação do modelo, mas sem se vislumbrarem caminhos para uma outra prática, sobretudo por decorrência da organização dos serviços de saúde e da formação profissional, que não respaldam a construção do conhecimento sobre adolescência e sociedade como socialmente construídas, portanto, passíveis de modificação.

Avaliamos que precisam ser criadas possibilidades, aos profissionais de saúde da ESF, de repensarem suas concepções, a partir do lugar que ocupam no mundo do trabalho, de modo que considerem múltiplas variáveis no entendimento da adolescência. Sem que se propiciem momentos de reflexão sobre o sentido de adolescência, mantém-se o imobilismo ou desenvolvem-se ações pouco efetivas, ficando mais uma vez essa população na invisibilidade, com um não lugar na formação e nos serviços de saúde.

\section{Colaboradores}

Débora Cristina Fonseca participou da elaboração do artigo, de sua discussão, redação e revisão do texto. Sérgio Ozella participou da discussão e revisão do manuscrito. 


\section{Referências}

ABERASTURY, A.; KNOBEL,M. Adolescência normal. Porto Alegre: Artes médicas, 1989.

AGUIAR, W.M.J.; OZELLA, S. Desmistificando a concepção de adolescência. Cad. Pesqui., v.38, n.133, p.97-124, 2008.

Núcleos de significação como instrumento para a apreensão da constituição dos sentidos. Psicol. Cienc. Prof., v.26, n.2, p.222-45, 2006.

ASSIS, S.G. et al. A representação social do ser adolescente: um passo decisivo na promoção da saúde. Cienc. Saude Colet., v.8. n.3, p.669-80, 2003.

AVILA, G.I.G. Políticas Públicas e Programas de Saúde para o adolescente latinoamericano: a enfermagem nos casos de Brasil e Colômbia. 1999. Tese (Doutorado) Escola de Enfermagem Anna Nery, Universidade Federal do Rio de Janeiro, Rio de Janeiro. 1999.

AYRES, J.R.C.M. Da necessidade de uma prática reflexiva sobre o cuidado: a hermenêutica como acesso ao sentido das práticas de saúde. In: PINHEIRO, R.; MATOS, R.A. (Orgs.). Razões públicas para a integralidade em saúde: o cuidado como valor. Rio de Janeiro: IMS/UERJ, Cepesc, Abrasco, 2007. p.127-44.

AYRES, J.R.C.M.; FRANÇA JÚNIOR, I. Saúde do adolescente. In: SCHRAIBER, L.B.; NEMES, M.I. B. (Orgs.). Saúde do adulto: programas e ações na unidade básica. São Paulo: Hucitec, 2000, p.66-85.

BASTOS, A.S. Visões acerca dos adolescentes: algumas concepções na área da Saúde. 2003. Dissertação (Mestrado) - Departamento de Saúde Materno-Infantil, Faculdade de Saúde Pública, Universidade de São Paulo, São Paulo. 2003.

BLASCO, J.P. Una revisión de la idea de adolescencia como etapa de crisis y turbulencia. In: CONGRESO INTERNACIONAL DE LA ASOCIACIÓN NACIONAL DE PSICOLOGÍA EVOLUTIVA Y EDUCATIVA DE LA INFANCIA Y LA ADOLESCENCIA (INFAD), 7., 1997, Oviedo. Anais... Oviedo, 1997. p.142-50.

BOCK, A.M.B.; AGUIAR, W.M.J. Psicologia da educação: em busca de uma leitura crítica e de uma atuação compromissada. In: BOCK, A.M.B. (Org.). A perspectiva sóciohistórica na formação em psicologia. Petrópolis: Vozes, 2003. p.132-60.

BRASIL. Ministério da Saúde. Política Nacional de Atenção à Saúde de Adolescentes e Jovens. Brasília: Ministério da Saúde, 2007.

CALAZANS, G. Cultura adolescente e saúde: perspectivas para a investigação. In: OLIVEIRA, M.C. (Org.). Cultura, adolescência, saúde: Argentina, Brasil, México. Campinas: Consórcio de Programas em Saúde Reprodutiva e Sexualidade na América Latina (Cedes /Colmex/Nepo - Unicamp), 2000. p.44-97.

CANO, M.A.T. et al. A produção do conhecimento sobre adolescência na enfermagem: período 1983 a 1996. Rev. Latino-am. Enferm., v.6, n.1, p.91-7, 1998.

CATHARINO, T.R. Da gestão dos riscos à invenção do futuro: considerações médicopsicológicas e educacionais sobre histórias de meninas que engravidam entre 10 e 14 anos. 2002. Tese (Doutorado) - Instituto de Psicologia, Universidade de São Paulo, São Paulo. 2002.

FERRARI, R.A.P.; THONSON, Z.; MELCHIOR, R. Atenção à saúde dos adolescentes: percepção dos médicos e enfermeiros das equipes de saúde da família. Cad. Saude Publica, v.22, n.11, p.2491-5, 2006.

FONSECA, D.C. Os profissionais da Estratégia de Saúde da Família (ESF) e a construção de sentidos sobre adolescência. 2008. Tese (Doutorado) - Programa de Psicologia Social, Pontifícia Universidade Católica de São Paulo, São Paulo. 2008.

FORMIGLI, V.L.A.; COSTA, M.C.O.; PORTO, L.A. Avaliação de um serviço de atenção integral à saúde do adolescente. Cad. Saude Publica, v.16, n.3, p.831-41, 2000. 
FRIEDMAN, S. Uma aproximação metodológica ao estudo das emoções. In: LANE, S.; SAWAIA, B.B. (Orgs.). Novas veredas da psicologia social. São Paulo: Brasiliense, 1995. p.135-46.

HEIDEMANN, M. Adolescência e saúde: uma visão preventiva para profissionais de saúde e educação. Petrópolis: Vozes, 2006.

LEÃO, L.M.S. Saúde do adolescente: atenção integral no plano da utopia. 2005. Dissertação (Mestrado) - Centro de Pesquisas Aggeu Magalhães, Fundação Oswaldo Cruz, Recife. 2005.

LEONTIEV, A.N. Actividad, consciencia y personalidad. Buenos Aires: Ciências Del Hombre, 1978.

LURIA A.R. Pensamento e linguagem: as últimas conferências de Luria. Porto Alegre: Artes Médicas, 2001.

MARCELLI, D.; BRACONNIER, A. Adolescência e psicopatologia. 6.ed. Porto Alegre: Artmed, 2007.

MARTINS, S.T.F. O materialismo histórico e a pesquisa-ação em psicologia social e saúde. In: ABRANTES, A.; MARTINS, S.T.F.; SILVA, N.R. (Orgs.). Método histórico-social na psicologia social. Petrópolis: Vozes, 2005. p.139-54.

MENDONÇA, M.H.M. O desafio da política de atendimento à infância e à adolescência na construção de políticas públicas eqüitativas. Cad. Saude Publica, v.18, supl., p.11320, 2002.

OLIVEIRA, M.A.C.; EGRY, E.Y. A adolescência, o adolescer e o adolescente: re-significação a partir da determinação social do processo saúde-doença. Rev. Bras. Enferm., v.51, n.4, p.643-654, 1998.

OZELLA, S. A adolescência e os psicólogos: a concepção e a prática dos profissionais. In: _. (Org.). Adolescências construídas: a visão da psicologia sócio-histórica. São Paulo: Cortez, 2003. p.17-40.

Adolescência: uma perspectiva crítica. In: CONTINI, M.L.J.; KOLLER, S.H.; BARROS, M.N.S. (Orgs.). Adolescência e psicologia: concepções, práticas e reflexões críticas. Rio de Janeiro: Conselho Federal de Psicologia, 2002. p.16-22.

PERES, F.; ROSENBURG, C.P. Desvelando a concepção de adolescência/adolescente presente no discurso da saúde pública. Saude Soc., v.1, n.7, p.53-86, 1998.

SILVA, J.L.P.; PINOTTI, J.A. A adolescência e o sistema de saúde. Femina,v.15, n.8, p.640-2, 1987.

TAQUET, S.R. et al. Conflitos éticos no atendimento à saúde de adolescente. Cad. Saude Publica, v.21, n.6, p.1717-25, 2005.

VENTURA, M.; CORRÊA, S. Adolescência, sexualidade e reprodução: construções culturais, controvérsias normativas, alternativas interpretativas. Cad. Saude Publica, v.22, n.7, p.1505-9, 2006.

VIGOTSKI, L.S. A construção do pensamento e da linguagem. Trad. Paulo Bezerra. São Paulo: Martins Fontes, 2001. 1984.

Obras escogidas IV: psicologia infantil. 2.ed. Moscú: Editorial Pedagógica,

Obras Escogidas III: problemas del desarrollo de la psique. Moscú: Editorial Pedagógica, 1983.

Obras Escogidas II. Moscú: Editorial Pedagógica, 1982. 
FONSECA, D.C.; OZELLA, S. Los conceptos de la adolescencia construidos por profesionales de la Estrategia de Salud de la Familia (ESF). Interface - Comunic., Saude, Educ., v.14, n.33, p.411-24, abr./jun. 2010.

Este trabajo examina los sentidos construidos sobre adolescencia con sus implicaciones en la práctica de médicos y enfermeros integrantes de la Estrategia de Salud de la Familia (ESF) de un municipio del estado brasileño de São Paulo. El análisis, con base en entrevistas, constata que el inmovilismo para acciones conjuntas se refuerza por el predominio de la visión natural, universal y patológica que coloca a la adolescencia fuera del lugar del cotidiano de los equipos de salud de la familia. Por ello surge la necesidad de pensar nuevamente las concepciones a partir del lugar que tales profesionales ocupan en el mundo del trabajo.

Palabras clave: Adolescencia. Salud de la Familia. Psicología sócio-histórica. Formación de recursos humanos.

Recebido em 03/02/09. Aprovado em 09/12/09. 